\title{
Signaling from Axon Guidance Receptors
}

\author{
Greg J. Bashaw ${ }^{1}$ and Rüdiger Klein ${ }^{2}$ \\ ${ }^{1}$ Department of Neuroscience, University of Pennsylvania School of Medicine, Philadelphia, \\ Pennsylvania 19104 \\ ${ }^{2}$ Max-Planck-Institute of Neurobiology, Department of Molecular Neurobiology, \\ Am Klopferspitz 18, 82152 Munich-Martinsried, Germany \\ Correspondence: gbashaw@mail.med.upenn.edu
}

\begin{abstract}
Determining how axon guidance receptors transmit signals to allow precise pathfinding decisions is fundamental to our understanding of nervous system development and may suggest new strategies to promote axon regeneration after injury or disease. Signaling mechanisms that act downstream of four prominent families of axon guidance cues-netrins, semaphorins, ephrins, and slits-have been extensively studied in both invertebrate and vertebrate model systems. Although details of these signaling mechanisms are still fragmentary and there appears to be considerable diversity in how different guidance receptors regulate the motility of the axonal growth cone, a number of common themes have emerged. Here, we review recent insights into how specific receptors for each of these guidance cues engage downstream regulators of the growth cone cytoskeleton to control axon guidance.
\end{abstract}

enerating precise patterns of connectivity
depends on the regulated action of con-
served families of guidance cues and their neu-
ronal receptors. Activation of specific signaling
pathways can promote attraction, repulsion,
result in growth cone collapse, or affect the
rate of axon extension through signaling events
that act locally to modulate cytoskeletal dynam-
ics in the growth cone. Here, we review recent
insights into how specific guidance receptors
from each of the four "classic" guidance path-
ways engage downstream regulators of the
growth cone cytoskeleton with a particular
emphasis on Rho family small GTPases. We
begin with a consideration of how events at
the growth cone plasma membrane, including endocytosis and proteolytic processing, influence guidance receptor activation and signaling and then discuss how bidirectional links between receptors and cytoplasmic signaling molecules control axon guidance responses.

\section{ENDOCYTOSIS}

Endocytosis may be a necessary aspect of guidance receptor activation and signaling. In the case of membrane-associated ephrins, endocytosis of the ephrin-Eph complex is required for efficient cell detachment ( parallel to proteolytic cleavage, see the following). Vav family guanine nucleotide exchange factors (GEFs) have been implicated as regulators of Eph receptor

Editors: Marc Tessier-Lavigne and Alex L. Kolodkin

Additional Perspectives on Neuronal Guidance available at www.cshperspectives.org

Copyright (C) 2010 Cold Spring Harbor Laboratory Press; all rights reserved; doi: 10.1101/cshperspect.a001941

Cite this article as Cold Spring Harb Perspect Biol 2010;2:a001941 
endocytosis and/or signaling. Neurons lacking Vav2 and Vav3 fail to respond to soluble ephrinA-Fc proteins with growth cone collapse and do not endocytose the ephrinA/EphA complex. Vav2 ${ }^{-/-}$Vav3 $^{-/-}$mice show defects in the retinogeniculate map consistent with a role as mediators of Eph repulsive signaling (Cowan et al. 2005). Vav proteins may trigger Eph internalization into signaling endosomes from where Eph receptors mediate dynamic changes of the actin cytoskeleton underlying growth cone collapse (Fig. 1A). Alternatively, Vav proteins may act in concert with other regulators of Rho GTPases to regulate Eph repulsive signaling independent of endocytosis (see later). For ephrinB-EphB-induced repulsive guidance, efficient cell detachment requires bidirectional endocytosis (Fig. 1B). Vav proteins may primarily promote cell detachment by mediating local Rac-dependent endocytosis of the ephrin-Eph complex and membrane. Neuronal growth cone collapse was observed, but detachment from a target cell was delayed when the target cell expressed a carboxy terminally truncated Eph. This mutant Eph receptor, unlike its fulllength counterpart, failed to undergo forward ephrin-Eph endocytosis, resulting in inefficient removal of the ephrin-Eph complex from the cell surface (Zimmer et al. 2003).

Endocytosis may also be part of an adaptation process that resets the growth cone's sensitivity to a repulsive cue. Adaptation in Xenopus retinal growth cones to Sema3A or netrin-1 involves two processes: A fast desensitization,
A

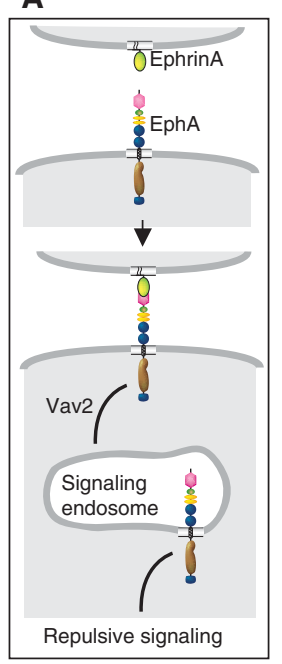

B

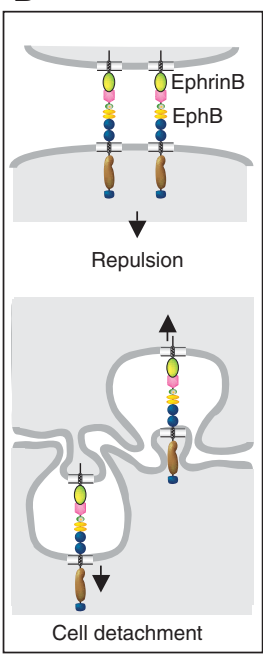

C

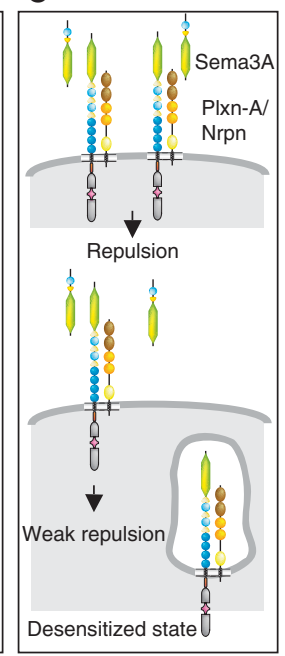

D

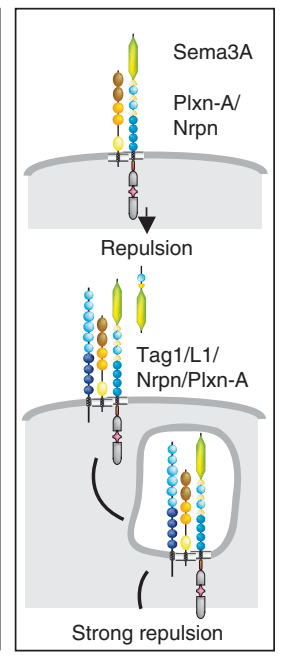

E

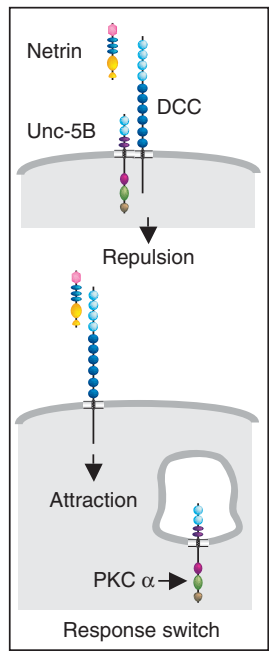

Figure 1. Regulation of guidance receptor activation and signaling by endocytosis. $(A)$ In response to ephrin binding to Ephs, the Rho family GEF Vav2 is recruited to the activated Eph receptor. Vav family GEFs are required for EphA endocytosis and ephrinAl-induced growth cone (GC) collapse, suggesting a role for Vavs in trafficking Ephs into signaling endosomes. (B) EphrinB binding to EphBs in neuronal GCs leads to collapse triggered by Eph forward signaling. Bi-directional endocytosis is necessary to remove the Ephrin-Eph protein complex from the cell surface, thereby allowing efficient cell detachment. $(C)$ Endocytosis is a mechanism by which GCs adapt to guidance cues. Xenopus retinal GCs undergo collapse in response to Sema3A binding to its receptors Plxn-A and Nrpn. Exposure to a low dose of Sema3A desensitized the GCs, because Sema3A receptors were rapidly endocytosed. $(D)$ Neural cell adhesion molecules (CAMs) such as L1 and TAG-1 modulate the response of certain axons to Sema3A. L1 binding to Nrpn (shown) and TAG-1 binding to L1 (not shown) facilitate internalization of Sema3A receptors, thereby enhancing the sensitivity of the GCs to Sema3A. (E) Endocytosis switches chemorepulsion to chemoattraction. Chemorepulsion by netrin is mediated by a complex of DCC and Unc5 receptors, whereas chemoattraction of netrin is mediated by DCC alone. Activation of protein kinase $\mathrm{C} \alpha(\mathrm{PKC} \alpha)$ specifically promotes internalization of the repellent Unc5 receptor, thereby converting netrin-mediated repulsion to attraction. 
which is dependent on receptor endocytosis, and a slower resensitization, which is dependent on protein synthesis (Fig. 1C). If background levels of a particular guidance cue increase, growth cones make use of this adaptation mechanism to tune their responsiveness appropriately to higher levels of the guidance cue riding on top of the background levels (Piper et al. 2005).

Endocytosis of guidance receptors is also influenced by other membrane receptor systems and can lead to changes in responsiveness to the guidance cue. The cell adhesion molecules L1 and TAG-1 promote Sema3A activity through interaction and coendocytosis with its receptor neuropilin-1 (Nrpn-1). Cortical axons from L1-deficient mice no longer respond to Sema3A (Castellani et al. 2000) and sensory nociceptive neurons lacking TAG-1 or L1 show reduced sensitivity to ventral spinal cord chemorepellents, including Sema3A (Fig. 1D) (Law et al. 2008). Hence, CAMs represent cell-cell communication cues that can modulate responses to long-range diffusible molecules.

Activation of protein kinase $\mathrm{C} \alpha(\mathrm{PKC} \alpha)$ converts netrin-1-mediated chemorepulsion to chemoattraction by specifically internalizing the repellent UNC5A receptors from the cell surface; the remaining attractant DCC receptors mediate the chemoattractive response to netrin-1 (Fig. 1E) (Bartoe et al. 2006). Here, in contrast to desensitization, the endocytosis of UNC5 is not triggered by its own ligand. Instead, activation of the $G$ protein coupled Adenosine 2B (A2b) receptor leads to the PKC dependent endocytosis of UNC5 (McKenna et al. 2008). Although the role of $A 2 b$ in netrin signaling has been quite controversial (Bouchard et al. 2004; Corset et al. 2000; Shewan et al. 2002; Stein et al. 2001), in the context of UNC5 regulation, A2b acts independently of netrin, and its ability to regulate UNC5 surface levels support a role as a potent modulator of netrin responses.

\section{PROTEOLYTIC PROCESSING AND RECEPTOR SIGNALING}

Like endocytosis, proteolytic processing contributes to receptor activation and modulates guidance responses (Fig. 2). For instance, preventing the metalloprotease-dependent ectodomain shedding of DCC results in enhanced DCC expression and potentiates netrin-induced axon outgrowth (Galko and Tessier-Lavigne 2000). A number of studies have implicated Kuzbanian (Kuz)/ADAM10 family proteases in the signaling pathways of guidance receptors. For example, Kuz/Adam10 regulates the cleavage of Eph receptors and ephrinA2 ligands. Adam10 forms a stable complex with ephrinA2 and on Eph interaction with ephrinA2, the resulting ligand-receptor complex is cleaved by Adam10 (Hattori et al. 2000) (Fig. 2A). More recently, the mechanism that allows cleavage of only those ephrin ligands that are engaged by receptors has been elucidated (Janes et al. 2005). Ligand/receptor binding exposes a new recognition sequence for Adam 10, resulting in the optimal positioning of the protease domain with respect to the substrate (Janes et al. 2005). This mechanism explains how an initially adhesive interaction can be converted to repulsion and offers an efficient strategy for axon detachment and attenuation of signaling. The matrix metalloprotease family can also convert ephrinB/EphB adhesion into axon retraction by specific cleavage of the EphB2 receptor (Lin et al. 2008). Thus, both ephrin ligands and Eph receptors can be substrates for regulated proteolysis and these events are critical in mediating axon retraction. Kuz has also been implicated in Slit-robo mediated repulsion in Drosophila. Specifically, ectopic midline crossing of ipsilateral interneurons, a hallmark of defective midline repulsion, is observed in kuz zygotic mutant embryos and dose-dependent interactions between $k u z$ and slit suggest that Kuz may be a positive regulator of Slit-Robo signaling (Schimmelpfeng et al. 2001). This raises the intriguing possibility that Kuz may regulate guidance by regulating the cleavage of Slit or Robo (Fig. 2D).

Kuz was identified in Drosophila for its role in regulating Notch signaling during neurogenesis (Pan and Rubin 1997; Rooke et al. 1996). Kuz cleavage of Notch releases the extra-cellular domain and triggers the subsequent cleavage and 
G.J. Bashaw and R. Klein
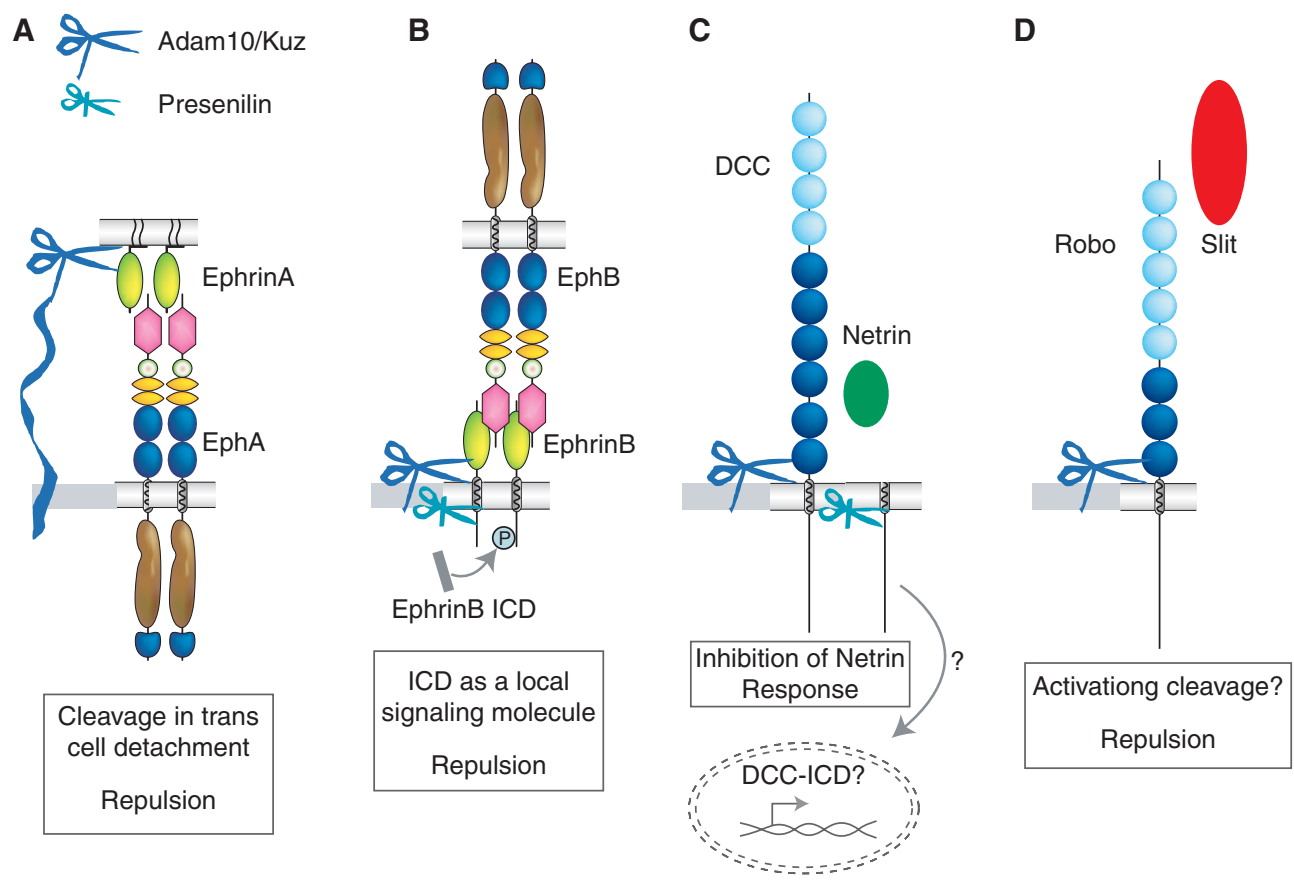

Figure 2. Regulation of receptor activation and signaling by proteolytic processing. $(A)$ Following ligand-receptor complex formation, ADAM10 cleaves the ephrinA5 ligand. This regulated proteolytic event both leads to release from the initial cell-cell adhesion, allowing for growth cone retraction, and is necessary for the transduction of the EphA3 forward signal. (B) Processive cleavage of ephrinB leads to the release of the ephrinB intracellular domain (ICD), which may activate SRC-family kinases to contribute to reverse signaling. On the other hand, cleavage of the EphB2 receptor, in this case by matrix metalloproteases (not pictured), is required for receptor activation in vitro. $(C)$ Regulated proteolysis of DCC occurs by ADAM10-mediated creation of a carboxy-terminal fragment (CTF), followed by $\gamma$-secretase mediated intramembrane cleavage releasing DCC ICD. This ICD is competent to translocate to the nucleus when fused with Gal4. The cleavage event by ADAM10 leads to attenuation of neuritogenesis in vitro. $(D)$ Kuzbanian appears to act positively in the Slit-Robo signaling pathway. Based on genetic observations and the abnormal presence of Robo protein on the commissural portions of axons in kuz mutants, we speculate that Kuz may cleave Robo to regulate receptor activity.

release of the Notch intracellular domain (ICD) by the $\gamma$-secretase complex. This second cleavage event releases Notch ICD from the membrane, allowing it to translocate to the nucleus, where it acts as a transcriptional regulator (Mumm and Kopan 2000). Interestingly, a number of in vitro studies have shown that DCC (Parent et al. 2005; Taniguchi et al. 2003) and several ephrin ligands and Eph receptors appear to undergo a similar Adam $10 / \gamma$-secretase sequential proteolysis (Georgakopoulos et al. 2006; Litterst et al. 2007; Tomita et al. 2006) and that preventing these processing events leads to deficits in the in vitro activities of these guidance molecules. Several observations hint at potentially important regulatory activities of released receptor ICDs. For instance, a DCC ICD fused with a Gal4 DNA binding domain can initiate $\gamma$-secretasedependent transcription, suggesting that the DCC ICD could regulate transcription (Taniguchi et al. 2003) (Fig. 2C), whereas ephrin's ICD can bind to and locally activate Src family kinases (Georgakopoulos et al. 2006) (Fig. 2B). If and how these processing events contribute to in vivo receptor function will be an important area of future research. 


\section{SECOND MESSENGERS AND AXON GUIDANCE RECEPTOR SIGNALING}

Calcium $\left(\mathrm{Ca}^{++}\right)$and cyclic nucleotides (cAMP and cGMP) can act in vitro to directly mediate guidance receptor signaling and also can modulate the strength and valence of guidance responses. Disruption of $\mathrm{Ca}^{++}$and cyclic nucleotide signaling leads to guidance defects in many systems and in some cases direct links have been made to specific guidance receptor signaling pathways. These two signaling systems show extensive cross talk in the regulation of growth cone guidance: $\mathrm{Ca}^{++}$signaling can promote the production of cyclic nucleotides through activation of soluble adenylyl cyclases and nitric oxide synthase (NOS) and cyclic nucleotides can regulate cellular calcium concentration by controlling the activity of plasma membrane $\mathrm{Ca}^{++}$channels as well as through the regulation of calcium-induced calcium release (CICR) from internal stores (Gomez and Zheng 2006; Zheng and Poo 2007). This positive feedback could potentially play a role in amplifying responses to shallow gradients of guidance cues.

\section{CALCIUM}

Exposure of growth cones to in vitro gradients of guidance cues can induce a corresponding gradient of $\mathrm{Ca}^{++}$elevation (Gomez and Zheng 2006; Henley and Poo 2004). These asymmetric changes in $\mathrm{Ca}^{++}$concentrations appear to be instructive signals to direct growth cone turning, because focal elevation of $\mathrm{Ca}^{++}$is sufficient to induce turning responses (Zheng 2000). Increases in $\mathrm{Ca}^{++}$influx and CICR can be triggered by guidance cues and the outcome for growth cone behavior (either attraction or repulsion) can be influenced by the magnitude of the $\mathrm{Ca}^{++}$elevation, the slope of the $\mathrm{Ca}^{++}$ gradient, and potentially the specific source of the $\mathrm{Ca}^{++}$as well (Gomez and Zheng 2006; Zheng and Poo 2007). In general, moderate amplitude increases in $\mathrm{Ca}^{++}$(often involving CICR) favor attraction, whereas high or low amplitude increases favor repulsion, although differences in neuron type, growth substrate,
Signaling from Axon Guidance Receptors

and resting $\mathrm{Ca}^{++}$concentrations can affect growth cone responses. Although much of the strongest evidence for the importance of $\mathrm{Ca}^{++}$ signaling during chemotropic axon guidance comes from studies of cultured neurons, examples are accumulating that support the in vivo significance of a number of the key in vitro observations.

Electrophysiological recordings from growth cones indicate that attractive and repulsive guidance cues trigger rapid and reciprocal changes in membrane potential; attractants such as BDNF and Netrin lead to membrane depolarization and repellants such as Slit and Semaphorin lead to hyperpolarization (Henley et al. 2004; Li et al. 2005; Nishiyama et al. 2008; Wang and Poo 2005) (Fig. 3). Moreover, the polarity of the change in membrane potential determines attraction versus repulsion (Nishiyama et al. 2008). For Netrin and BDNF mediated attraction, transient receptor potential (TRP) $\mathrm{Ca}^{++}$channels contribute to membrane depolarization, and $\mathrm{Ca}^{++}$influx through these channels is required for chemoattraction (Li et al. 2005; Wang and Poo 2005) (Fig. 3A). Although earlier work had shown that Netrin induces $\mathrm{Ca}^{++}$influx in part through voltage-dependent calcium channels (VDCCs) (Hong et al. 2000), it remained unclear how Netrin stimulation results in adequate membrane depolarization to activate these channels. RNA interference and pharmacological manipulations in cultured Xenopus neurons indicate that BDNF and Netrin, through engagement of their respective $\operatorname{TrkB}$ and DCC receptors lead to $\mathrm{Ca}^{++}$release from internal stores and activation of TRP channels: The subsequent TRP channel-dependent membrane depolarization is sufficient to activate VDCCs and the resulting $\mathrm{Ca}^{++}$influx is essential for attractive turning. Importantly, TRP channels mediate axon guidance in vivo as well; morpholino antisense knockdown of TRPC1 reduces contralateral projections of Xenopus commissural interneurons, likely reflecting a requirement in Netrin-dependent midline crossing (Shim et al. 2005). A role for Semaphorins in activation of cyclic nucleotide gated (CNG) calcium channels strengthens the case 


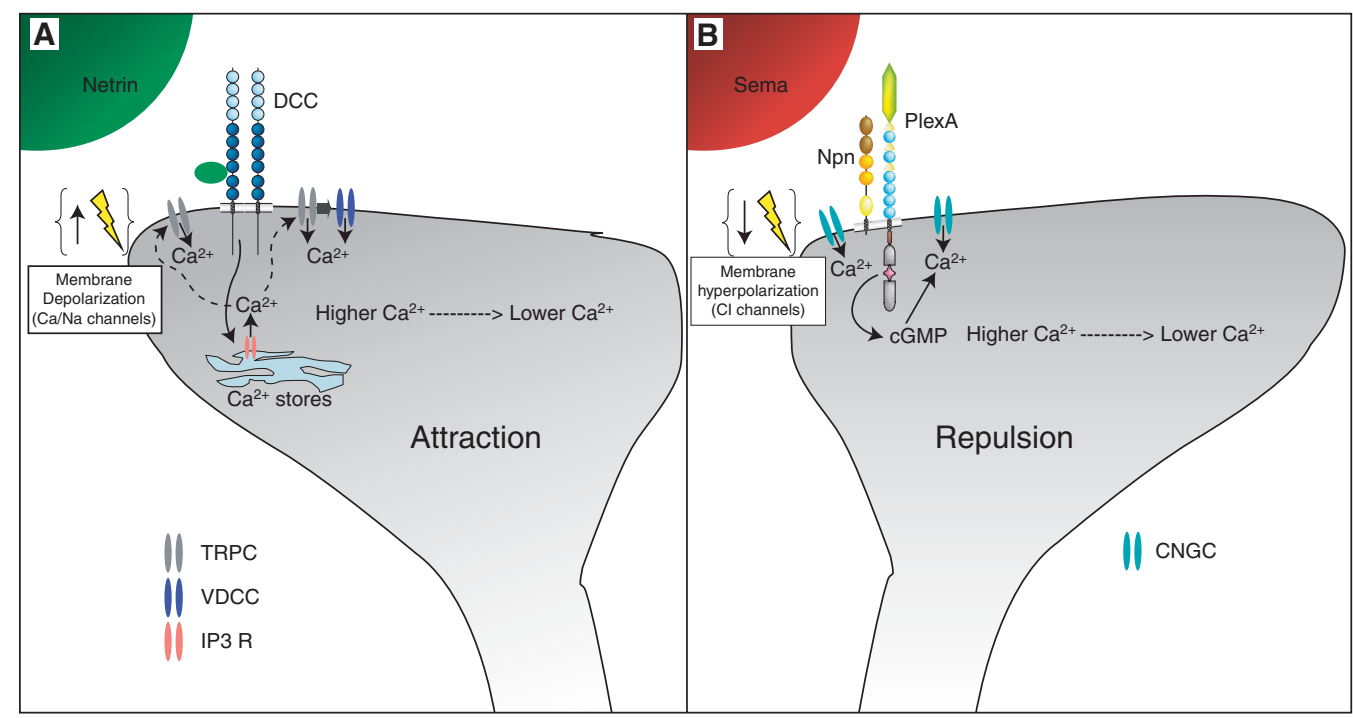

Figure 3. Second messengers and guidance receptor signaling. (A) In vitro application of chemoattractants like Netrin and BDNF (not pictured) leads to rapid membrane depolarization and triggers an asymmetric elevation of intracellular calcium on the side of the growth cone facing the source of the chemoattractant. Activation of DCC (or TRK receptors for BDNF) leads to the release of calcium from intracellular stores through IP3 receptors, which in turn activates plasma membrane TRP channels and voltage-dependent calcium channels (VDCC). The resulting gradient of intracellular calcium directs growth cone attraction. (B) In vitro application of chemorepellants like Semaphorin and Slit (not pictured) leads to rapid membrane hyperpolarization and a local elevation of intracellular calcium. Activation of PlexA receptors leads to the production of cGMP (likely through nitric oxide synthase), which in turn activates cyclic nucleotide gated (CNG) channels in the plasma membrane. In this case, the gradient of calcium and cGMP across the growth cone leads to growth cone repulsion.

for the specific regulation of calcium influx through plasma membrane channels and points to the importance of cross regulation of cyclic nucleotide and calcium signaling (Togashi et al. 2008) (Fig. 3B). Here, Sema signaling through Plexin receptors stimulates the production of cyclic GMP (cGMP), which in turn is required for membrane hyperpolarization, the activation of CNG channels, and growth cone repulsion (Nishiyama et al. 2008; Togashi et al. 2008). It will be interesting to see to what extent CNG channels contribute to repulsive axon guidance in vivo.

\section{CYCLIC NUCLEOTIDES}

Like calcium signaling, cyclic nucleotides (cAMP or cGMP) can have profound effects on growth cone responses to guidance cues. The levels of cyclic nucleotides, specifically the ratio of cAMP to cGMP, can determine whether the response to a guidance cue will be attractive or repulsive, with high cyclic nucleotide levels (or high cAMP/cGMP ratios) favoring attraction and low levels (or low cAMP/cGMP ratios) favoring repulsion (Nishiyama et al. 2003; Song et al. 1998; Song et al. 1997). Although a clear demonstration that cyclic nucleotide signaling can convert receptor responses from attraction to repulsion and vice versa in vivo is still lacking, cyclic nucleotide signaling can clearly modulate the strength of receptor responses. For example, during motor axon guidance in Drosophila, cAMP signaling through protein kinase A (PKA) can modulate axon repulsion. Specifically, the Drosophila A-kinase anchoring protein (AKAP), Nervy, links the Plexin-A receptor to PKA to inhibit sema repulsion (Terman and Kolodkin 2004). Together with a number of recent studies in zebrafish and in cultured 
neurons that suggest a similar inhibitory effect of cAMP/PKA on the strength of repulsive guidance signals, the role of nervy in Sema signaling suggests that cyclic nucleotide signaling reduces the strength of guidance outputs (Chalasani et al. 2003; Chalasani et al. 2007; Dontchev and Letourneau 2002).

In these examples, the signals mediating changes in cyclic nucleotide levels are independent of the guidance receptors whose outputs they regulate; however, more direct roles for cAMP or cGMP signaling downstream of specific guidance signals have been suggested. For instance, as mentioned previously, SemaPlexin signaling leads to the production of cGMP, and cGMP plays an instructive role in promoting repulsion by regulating membrane hyperpolarization and the influx of $\mathrm{Ca}^{++}$through CNG channels. Genetic studies of motor axon guidance in Drosophila support an in vivo requirement for cGMP signaling during SemaPlexin repulsion; mutations in a receptor guanylyl cyclase Gyc76C lead to motor axon guidance defects that are similar to those observed in sema and plexin mutants, and genetic interactions indicate that Gyc76C acts in the SemaPlexin pathway (Ayoob et al. 2004). In the case of Netrin, pharmacological manipulations in cultured Xenopus neurons have shown that Netrin outgrowth and attraction require DCC (or A2b)-mediated elevation of cAMP and activation of PKA (Corset et al. 2000; Hopker et al. 1999). More recently, soluble adenylyl cyclase has been shown to regulate the production of cAMP in response to Netrin in rat DRG neurons (Wu et al. 2006). However, other studies in rodent commissural neurons support a different role for cAMP/PKA in contributing to Netrin responses and have shown: (1) that Netrin does not lead to elevations in cAMP levels or activation of PKA, (2) that PKA is not required for Netrin attraction, but instead regulates the Netrin response through promoting DCC recruitment to the plasma membrane, and (3) that mutations in soluble adenylyl cyclase do not result in commissural axon guidance defects in mice (Bouchard et al. 2004; Moore and Kennedy 2006; Moore et al. 2008b). Although these observations do not preclude a role for direct Netrin-dependent cAMP signaling in other cellular contexts, such as in vitro steering of cultured Xenopus neurons, they do argue against the generality of this mechanism for Netrin-directed axon path finding in vivo. Together, the available evidence favors an important role for cyclic nucleotides in modulating the strength of guidance responses in vivo rather than switching the polarity of responses.

How do changes in intracellular $\mathrm{Ca}^{++}$and cyclic nucleotide signaling result in directed growth cone turning? Although a full discussion of the many downstream effectors of calcium and cyclic nucleotide signaling are well beyond the scope of this article, key targets include (1) kinases such as PKA, PKC, Src, and CamKinaseII, (2) calcineurin and PP1 protein phosphatases, (3) Calpain proteases, and 4) Rho-family small GTPases. Here, we emphasize the role of Rho GTPases in guidance receptor signaling because they are implicated as key players downstream of all of the "classical" axon guidance receptors, because considerable progress has been made in establishing direct links between Rho GTPases and guidance receptors, and because there is strong evidence from many model systems for the in vivo significance of Rho GTPase function in axon guidance receptor signaling.

\section{RHO FAMILY SMALL GTPases}

In this section, we discuss how guidance receptors are linked to activation of Rho GTPases through guanine nucleotide exchange factors (GEFs) and GTPase activating proteins (GAPs), and how these pathways in turn result in modulation of cytoskeletal dynamics to achieve specific guidance outcomes. For more extensive discussion of the role of Rho GTPases in neuronal development, we refer the reader to Hall and Lalli (2010).

Netrins, Semas, ephrins, and Slits all regulate the activity of Rho-family GTPases. Netrin, through DCC, increases Rac activity in fibroblasts (Li et al. 2002), increases Rac and Cdc42 activity in rat commissural neurons (Shekarabi et al. 2005), and inhibits RhoA activity (Moore 
et al. 2008a). Sema treatment via plexin-B1 results in activation of RhoA (Swiercz et al. 2002) and sequestering of active Rac (Hu et al. 2001); however, Sema3A via plexin-A activates Rac, but not RhoA (Turner et al. 2004). Ephrins, through Eph receptors, result in increased RhoA activity as well, but also cause transient, decreased Rac activity in retinal ganglion cells (RGCs) (Jurney et al. 2002; Wahl et al. 2000), whereas Eph-ephrin reverse signaling activates $\mathrm{Rac}$ and Cdc42 to direct repulsive axon pruning (Xu and Henkemeyer 2009). Slits, acting through Robo receptors, lead to Rac and Rho activation and inhibition of Cdc42 (Fan et al. 2003; Wong et al. 2001). Thus, there is no clear consensus for how Rho GTPases mediate repulsion, because these repulsive guidance pathways each influence RhoA, Rac, and Cdc42 activity in distinct ways. Considerable progress has been made in understanding how these diverse guidance signals are coupled to the Rho GTPases to affect their activity.

\section{NETRIN-DCC}

Genetic analysis in Caenorhabditis elegans supports a role for Rac downstream of DCCmediated attraction; mutations in the Rac gene ced-10 partially suppress defects caused by expression of a constitutively active form of the DCC receptor homolog, Unc-40 (Gitai et al. 2003). In vitro, Netrin induces the rapid activation of Rac1, Cdc42, and Pak1, which results in profound changes in growth cone morphology, leading to increased surface area and a greater number of filopodia ( $\mathrm{Li}$ et al. 2002; Shekarabi and Kennedy 2002; Shekarabi et al. 2005). Netrin increases the amount of a nonhydrolyzable GTP analog, GTP $\gamma$ S, bound to $\mathrm{Rac}$ and Cdc42 in commissural neurons, suggesting that one or more GEFs may be associated with the DCC receptor to drive the observed increases in Rac and Cdc42 activity. In certain cell types, the Trio GEF may fulfill this function. Trio is an important regulator of axon guidance decisions in several contexts (Liebl et al. 2000; Newsome et al. 2000). Trio positively contributes to midline axon crossing in the embryonic CNS in Drosophila and can physically interact with Frazzled (Forsthoefel et al. 2005) and with mammalian DCC (Briançon-Marjollet et al. 2008), though in the latter case the interaction is likely mediated through binding to PAK-1. In contrast to wild-type, Netrin stimulation of cortical neurons from Trio - / - mice does not result in Rac activation and Trio $-/-$ mice also display guidance defects, which partially overlap with defects seen in netrin or DCC-/- mice (BriançonMarjollet et al. 2008). However, the commissural axon guidance defects in Trio-/- mutants are considerably milder than those in netrin or DCC $-/-$ mutants, indicating that additional factors must act in commissural neurons to transmit Netrin signals.

The CZH family GEF, DOCK180 also contributes to netrin-DCC attraction in mouse cortical and commissural neurons by mediating Rac activation. DOCK180 is required for dissociated cortical neuron outgrowth in response to netrin and for commissural neuron turning in explant assays ( $\mathrm{Li}$ et al. 2008), and knockdown of DOCK180 in chick spinal cords also reduces commissural axon midline crossing. Netrin can induce both axon outgrowth and attractive axon turning, therefore it is unclear in these assays whether commissural neuron turning defects are a secondary consequence of defects in axon outgrowth ( $\mathrm{Li}$ et al. 2008). Also unclear is whether Trio and DOCK180 act in the same or in a parallel pathway to mediate netrindependent Rac activation downstream of DCC. Both Trio and DOCK180 can interact with DCC, thus either may be sufficient to activate Rac after its recruitment to the receptor.

\section{SEMA-PLEXIN}

Genetic analysis of motor axon guidance in Drosophila indicates that PlexinB mediates repulsion in part by binding to active Rac. At sites where growth cones are exposed to Semaphorins, PlexinBs are clustered and sequester active Rac, thereby preventing Rac from binding to and activating p21-activated kinase (PAK) and inducing lamellipodia extension ( $\mathrm{Hu}$ et al. 2001). Work in cultured cells suggests that the interaction between PlexinB and Rac is 
Signaling from Axon Guidance Receptors

bi-directional: Active Rac enhances the affinity of Plexin-B1 for Sema4D and its localization at the cell surface (Vikis et al. 2002). Genetic evidence also indicated that PlexinB requires RhoA (Hu et al. 2001) and in cultured cells Plexin-B1 was shown to bind the Rho guanine nucleotide exchange factors PDZ-RhoGEF and LARG via its carboxy-terminal PDZ binding site (Swiercz et al. 2002). Binding of Sema$4 \mathrm{D}$ to plexin-B1 stimulates PDZ-RhoGEF/ LARG activity, resulting in activation of RhoA. Dominant-negative forms of PDZ-RhoGEF/ LARG block Sema4D-induced growth cone collapse in hippocampal neurons, thereby demonstrating the necessity of this pathway in primary neurons. How well-used this pathway is in vivo will have to await future genetic studies.

In contrast to Plexin-Bs, Plexin-A-induced growth cone repulsion requires the activation of Rac (Jin and Strittmatter 1997). Recent work in cultured sensory neurons delineated the pathway downstream of the Plexin-A/ Npn-1 complex that mediates Sema3A-induced suppression of neurite outgrowth (Toyofuku et al. 2005). The FERM domain-containing GEF protein, FARP2, associates with the Plexin-A1/Npn-1 complex. Sema3A binding to Npn-1 causes FARP2 to dissociate from Plexin-A1, activating FARP2's GEF activity and raising the levels of Rac-GTP in the cell. Through a combination of dominant-negative and siRNA knockdown experiments, it was shown that activation of Rac triggers Rnd1 binding to Plexin-A1, thereby activating Plexin-A1's intrinsic RasGAP activity. Activated Plexin-A1 down-regulates R-Ras activity, which may lead to inhibition of integrin function and growthcone repulsion. Whether FARP2 directly regulates cytoskeletal dynamics and whether FARP2 is a required effector for Plexin-A1-mediated axon guidance function in vivo remains to be shown. Interestingly, the related FERM domaincontaining GEF protein, FARP1, is enriched in the dendrites of lateral motor column neurons that innervate the limbs, where it specifically mediates dendritic growth downstream of transmembrane Sema6A and Plexin-A4 (Zhuang et al. 2009).

\section{EPHRIN-EPH FORWARD SIGNALING VIA THE DBL FAMILY GEF EPHEXIN1}

In the absence of ephrin stimulation, nonphosphorylated ephexin1 is bound to EphA4 and activates RhoA, Rac1, and Cdc42, leading to a balance of GTPase activation that promotes axonal growth (Fig. 4A) (Sahin et al. 2005). Eph tyrosine kinase activity is required, but not sufficient to promote ephexin1 phosphorylation; instead, ephrin-induced clustering of Ephs appears to promote ephexin1 phosphorylation (Egea et al. 2005), probably involving Src tyrosine kinase. Tyrosine phosphorylation of ephexin1 shifts its exchange activity toward RhoA, thereby causing growth cone collapse in vitro (Sahin et al. 2005). This provides a model of how ephexin 1 may steer growth cones: When Ephs are activated in a portion of the growth cone, tyrosine phosphorylated ephexin 1 may tip the local balance of GTPase activity toward RhoA, thereby causing actin depolymerization and local retraction (Fig. 4B). In other regions of the growth cone that have not made contact with ephrins, ephexin1 promotes growth by activating RhoA, Rac1, and Cdc42. The in vivo role of vertebrate ephexin 1 and the other four members of this family (ephexin2-5) are largely unexplored. But, this pathway appears to be evolutionarily conserved: the single Drosophila Eph receptor mediates synaptic homeostasis at the neuromuscular junction via ephexin (Frank et al. 2009).

\section{EPHRIN-EPH FORWARD SIGNALING VIA $\alpha 2-$ CHIMAERIN}

The Rac-specific GAP $\alpha 2$-chimaerin is an essential mediator of ephrinB3/EphA4 forward signaling in vivo. Loss of $\alpha 2$-chimaerin impairs repulsion of EphA4-expressing CST axons at the spinal cord midline and the formation of the spinal central pattern generator (CPG) (Beg et al. 2007; Shi et al. 2007; Wegmeyer et al. 2007; Iwasato et al. 2007). The association of $\alpha 2$-chimaerin with Eph receptors appears to be direct or mediated by the Nck2 (Grb4) adaptor protein. The latter mechanism is supported by the observation that mice lacking Nck1 and 
G.J. Bashaw and R. Klein
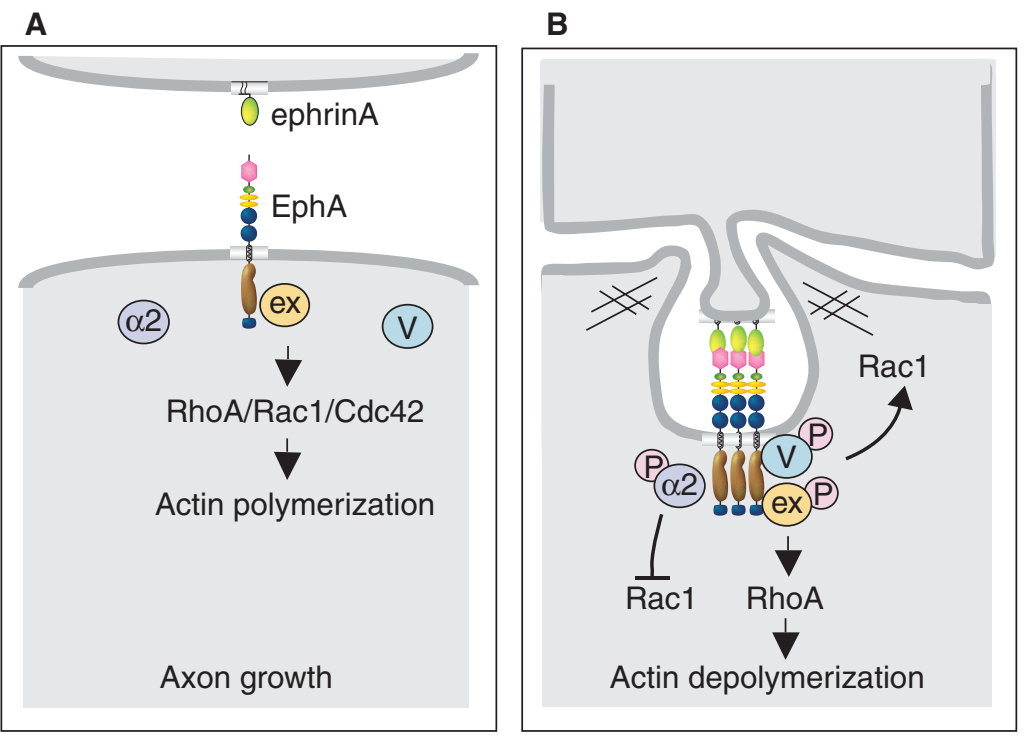

Axon retraction

Figure 4. Eph forward signaling via GEFs and GAPs. (A) In the absence of ephrin stimulation, ephexin1 (ex) is bound to Eph receptors and activates RhoA, Rac1, and Cdc42, leading to a balance of GTPase activation that promotes actin polymerization and axonal growth. $\alpha 2$-chimaerin $(\alpha 2)$ and Vav proteins $(\mathrm{V})$ do not bind unclustered Ephs. (B) Upon ephrin-induced clustering and autophosphorylation of Ephs, ephexin1 is tyrosine phosphorylated (P), which shifts its exchange activity toward RhoA. $\alpha 2$-chimaerin is recruited to the Eph cluster and becomes tyrosine phosphorylated. This modification activates its intrinsic GAP activity, causing inactivation of Rac1. RhoA activation and Racl inactivation promote actin depolymerization and axon retraction. The specific role of Vav-mediated Rac1 activation is currently unclear. It may be linked to Vavs role in Eph endocytosis and may help to polymerize actin near the plasma membrane, where the endocytic vesicle forms.

Nck2 in the nervous system display similar defects in CST and CPG formation as a2-chimaerin and EphA4 null mice (Fawcett et al. 2007). The interaction with EphA4 activates the intrinsic GAP activity of $\alpha 2$-chimaerin and this leads to inactivation of Rac1 (Fig. 4B). The cooperative action of $\alpha 2$-chimaerin in reducing Rac1-mediated actin polymerization and ephexin 1 in enhancing RhoA-mediated actin depolymerization appears to induce efficient axon retraction. Vav $2 / 3$ and $\alpha 2$-chimaerin have opposing effects on Racland yet both are mediators of EphA forward signaling. How can this paradoxical situation be explained? Unlike Vav2/3, $\alpha 2$-chimaerin does not influence Eph receptor endocytosis (Wegmeyer et al. 2007). It is possible that the activated Eph receptor first activates $\alpha 2$-chimaerin to induce axon retraction and then activates Vav2/3 to locally activate Rac1-dependent endocytosis to allow cell detachment.

\section{EPH-EPHRIN REVERSE SIGNALING}

Reverse signaling by receptor-like ephrinB proteins has been implicated in axon guidance (Henkemeyer et al. 1996). Following interactions with cognate Ephs, ephrinB proteins become clustered and signaling is initiated either by Src-mediated tyrosine phosphorylation of the ephrinB cytoplasmic tail or by recruitment of PDZ domain-containing effectors (Palmer et al. 2002). Nck2 is recruited to the phosphorylated ephrinB protein and is essential for several ephrinB-mediated processes, including spine formation (Cowan and Henkemeyer 2001; Segura et al. 2007). Nck1/ 2-deficient mice fail to develop a normal posterior branch of the anterior commissure, a phenotype previously attributed to defective ephrinB reverse signaling (Fawcett et al. 2007). Tyrosine phosphorylation-dependent ephrinB3 reverse signaling controls the stereotyped 
pruning of exuberant mossy fiber axons in the hippocampus and Nck2 has been implicated in this process. Nck2 appears to couple ephrinB3 to Dock180 and PAK, leading to activation of Rac1 and Cdc42 and downstream signaling that results in axon retraction/pruning ( $\mathrm{Xu}$ and Henkemeyer 2009).

\section{SLIT-ROBO}

Although inhibition of Rac can accompany repulsive guidance decisions, activation of Rac may also be involved in mediating responses to repulsive cues exemplified by Eph-dependent growth cone retraction and Ephrin-dependent axon pruning. In the context of Slit-Robo, mediated repulsion activation of Robo receptors by Slit leads to activation of Rac (Fan et al. 2003; Hu et al. 2005; Wong et al. 2001; Yang and Bashaw 2006), and limiting Rac function reduces the efficiency of Slit-Robo signaling (Fan et al. 2003; Hakeda-Suzuki et al. 2002). In Drosophila, specific Rac GAPs and GEFs directly link the Robo receptor to the regulation of Rac activity during axon repulsion at the midline, as well as during tracheal cell migration. Genetic analysis indicates that the conserved Rac GAP, Vilse/CrGAP, contributes to Slit-dependent guidance decisions in both CNS axons at the midline and in tracheal cells ( $\mathrm{Hu}$ et al. 2005; Lundstrom et al. 2004). Interestingly, in axons, high levels of Vilse overexpression causes similar defects to robo loss of function and low levels of overexpression cause dosage-dependent defects in Slit-Robo repulsion similar to loss of function of vilse ( $\mathrm{Hu}$ et al. 2005). Thus, the consequences of increasing or decreasing vilse function are similar: Both lead to a compromise in the efficiency of Slit-Robo midline repulsion, suggesting that the precise levels or spatial distribution of vilse Rac GAP activity may be instructive for Robo repulsion.

Although regulation of the GAP activity of Vilse/crGAP could potentially account for the observed increase in Rac-GTP following Robo receptor activation, vilse mutants lead to only subtle defects in midline repulsion. Considering that Rac activity is required for midline repulsion in the Drosophila CNS, additional regulators should link Robo to Rac activation in these neurons. The dual Ras-Rho GEF Sos is a likely candidate, based on its CNS expression, genetic interaction with slit and comm mutants (Fritz and VanBerkum 2000), and its interaction with the adaptor protein Nck (Dock in Drosophila), which binds to Robo and recruits Pak in Drosophila (Fan et al. 2003). Indeed, genetic evidence supports a role for sos in Robo signaling and Sos interacts biochemically with Robo via binding to the adaptor, Dock. In response to Slit treatment, the normally cytoplasmic Sos is recruited to the plasma membrane in cultured human 293 T cells, where it colocalizes with Robo and initiates membrane ruffling and lamellopodia formation (Yang and Bashaw 2006).

Based on this work and that described for forward Eph receptor signaling and reverse Ephrin ligand signaling, there are considerable parallels in how these repulsive guidance pathways regulate Rac activity. Both the Slit-Robo and the forward Eph pathway use a Rac GAP (Vilse for Robo and $\alpha$-chimaerin for Ephs) and a Rac GEF (Sos for Robo and Vav for Ephs) to mediate repulsion. A comparison of Robo signaling with ephrinB reverse signaling during axon pruning reveals that a complex of proteins including the adapter Nck (Dock in Drosophila), Pak, and Rac are recruited to the receptors to mediate repulsive signaling. Coordinated action of GEFs and GAPs may promote the cycling of Rac activity, which may be more important than the overall levels of Rac-GTP in a responding growth cone. Alternatively, these GAPs and GEFs may act in distinct signaling steps, as in the example of Eph receptors in which Vav-family GEFs mediate endocytosis of the ligand-receptor complex through Rac activation (Cowan et al. 2005). Rac activation in the case of Robo receptors may precede internalization as well, as intracellular accumulations of Sos and Robo have been observed in cultured cells (Yang and Bashaw, unpubl.).

\section{KINASE CASCADES}

Src family kinases (Src, Fyn, Yes, and others; collectively known as SFKs) are nonreceptor 
protein tyrosine kinases that have emerged as essential mediators of various guidance receptors. SFKs are critical for in vitro repulsive guidance of retinal ganglion and cortical axons downstream of EphA receptors, possibly mediating tyrosine phosphorylation of ephexin (Knöll and Drescher 2004; Zimmer et al. 2007). SFKs appear to be required in motor (LMC) axons for limb trajectory selection. Redirection of LMC axons by overexpressing either EphA4 or EphB2 was attenuated by inhibition of SFK function, suggesting that SFKs are critical for Eph forward signaling in vivo (Kao et al. 2009). Recruitment and activation of SFKs have been documented downstream of reverse signaling via GPI-anchored ephrinA ligands (Davy et al. 1999). Work in the moth Manduca sexta has shown that repulsion of migratory enteric neurons at the enteric midline is controlled by reverse signaling via the single GPI-anchored ephrin and that this process requires SFK function (Coate et al. 2009). The link between GPI-anchored ephrinAs and SFKs may be provided by transmembrane proteins such as $\mathrm{p} 75^{\mathrm{NTR}}$ and $\operatorname{TrkB}$ (Lim et al. 2008; Marler et al. 2008). At least in stably transfected cells, the presence of $p 75^{\mathrm{NTR}}$ enhanced ephrinA reverse signaling as witnessed by elevated phosphotyrosine and Fyn protein levels (Lim et al. 2008).

SFKs and focal adhesion kinase (FAK) are also essential mediators of Netrin signaling. On Netrin binding to DCC/Neogenin, Src/ Fyn and FAK are recruited to DCC, become activated by autophosphorylation, and induce tyrosine phosphorylation of the DCC cytoplasmic tail. Suppression of SFKs or FAK impaired neurite outgrowth and attractive turning responses of spinal cord and cortical neurons ( $\mathrm{Li}$ et al. 2004; Liu et al. 2004; Meriane et al. 2004; Ren et al. 2004). Because SFKs and FAK have pleiotropic roles downstream of many receptor systems, the in vivo relevance for these observations remains to be established. At least SFKs have been placed in the Netrin signaling pathway controlling cell migration by genetic studies in C. elegans (Itoh et al. 2005). An important SFK substrate, p130 ${ }^{\text {CAS }}$ (Crkassociated substrate), is required for Netrin- induced neurite outgrowth and axon attraction of cortical and spinal cord neurons (Liu et al. 2007). p130 ${ }^{\mathrm{CAS}}$ appears to act downstream of SFKs and upstream of the small GTPases Racl and Cdc42 (Liu et al. 2007). Fyn and Cdk5 also mediate Plexin-A/Npn1 signaling for growth cone collapse in DRG neurons. Moreover, the defects in cortical dendrite projections observed in Sema3A-/- mice were enhanced in Sema3A-/-; fyn -/- mice, suggesting that a signaling complex of PlexinA/SFKs/Cdk5 mediates Sema3A-induced guidance of cortical projections (Sasaki et al. 2002). Mutant Drosophila flies lacking endogenous SFKs (Src64B and Src42A) display commissure formation defects similar to those observed in Wnt5 and RYK/Derailed mutants. Complex formation between Derailed and Src leads to the activation of Src kinase activity and Derailed phosphorylation, suggesting that SFKs are mediators of Wnt5/Derailed signaling (Wouda et al. 2008). The morphogen Sonic hedgehog (Shh) mediates cell fate specification and axon guidance in the developing nervous system by two distinct pathways. Cell fate specification by Shh is mediated by the receptor Patched (Ptc) via the canonical pathway requiring the Gli family of transcription factors. In contrast, axon guidance by Shh is mediated by SFK in a Smoothened-dependent manner via a rapidly acting, noncanonical signaling pathway not requiring transcription (Yam et al. 2009).

\section{UPSTREAM REGULATORY ROLES FOR SECOND MESSENGERS AND RHO GTPases}

In addition to their critical contributions to downstream signaling, many recent studies have shown that second messengers and Rho GTPases can also influence guidance responses by regulating the surface localization and activation of guidance receptors (Allen and Chilton 2009). For instance, netrin stimulation leads to an increase in DCC surface levels and this effect is enhanced by protein kinase A (PKA) activation. Blocking either adenylate cyclase, PKA activity, or exocytosis prevents the increase in DCC surface levels and blunts netrin-induced axon outgrowth (Bouchard et al. 2004). In 
addition to PKA's role in regulating DCC, recent findings indicate that netrin-dependent inhibition of Rho activity also contributes to DCC membrane localilization (Moore et al. 2008a). Furthermore, genetic approaches in C.elegans have established that the trafficking and polarized localization of netrin and Slit receptors is critical for proper direction of axon outgrowth. Specifically, mutations in either the UNC-73 Trio-family RacGEF, its substrate the MIG-2 Rac small GTPase, or the VAB-8 kinesin-related protein disrupt the normal localization of the SAX-3 (Robo) and UNC-40 (DCC) receptors (Levy-Strumpf and Culotti 2007; Watari-Goshima et al. 2007). These perturbations in normal receptor localization lead to significant defects in Slit and netrin-dependent posterior oriented cell and growth cone migration, and further emphasize important upstream regulatory roles for Rho GTPases in the control of axon guidance receptor localization (Levy-Strumpf and Culotti 2007; Watari-Goshima et al. 2007). This unexpected upstream regulatory role must be carefully weighed when considering the outcome of Rho GTPase manipulations on axon guidance, especially because many earlier studies have assumed that by their very nature as regulators of the actin cytoskeleton that the Rho GTPases function exclusively as effectors of guidance signaling.

\section{CONCLUDING REMARKS}

The past decade has seen substantial progress in describing the mechanisms required to transmit axon guidance receptor signals. Although details of signaling pathways continue to emerge, our understanding of the key ligand-regulated events that control receptor activation and signaling is still fragmentary. Future progress will require the development of biochemical and optical strategies to uncover the dynamic changes in multi-protein signaling complexes that are triggered by guidance receptor activation. For instance, genetically encoded optical reporters for active forms of Rho GTPases, their effectors, and other signaling molecules will be instrumental in understanding the spatial and temporal dynamics of receptor signaling in vivo. It is also clear that many signaling and additional regulatory components await discovery, and biochemical, molecular, and genetic approaches in diverse experimental systems will continue to fill in the gaps in our knowledge.

\section{REFERENCES}

Allen J, Chilton JK. 2009. The specific targeting of guidance receptors within neurons: Who directs the directors? Dev Biol 327: 4-11.

Ayoob JC, Yu HH, Terman JR, Kolodkin AL. 2004. The Drosophila receptor guanylyl cyclase $\mathrm{Gyc} 76 \mathrm{C}$ is required for semaphorin-1a-plexin A-mediated axonal repulsion. J Neurosci 24: 6639-6649.

Bartoe JL, McKenna WL, Quan TK, Stafford BK, Moore JA, et al. 2006. Protein interacting with C-kinase 1/protein kinase $\mathrm{C} \alpha$-mediated endocytosis converts netrin-1mediated repulsion to attraction. J Neurosci 26: $3192-$ 3205.

Beg AA, Sommer JE, Martin JH, Scheiffele P. 2007. a 2 -Chimaerin is an essential EphA4 effector in the assembly of neuronal locomotor circuits. Neuron 55: 768-778.

Bouchard JF, Moore SW, Tritsch NX, Roux PP, Shekarabi M, et al. 2004. Protein kinase A activation promotes plasma membrane insertion of DCC from an intracellular pool: A novel mechanism regulating commissural axon extension. J Neurosci 24: 3040-3050.

Briançon-Marjollet A, Ghogha A, Nawabi H, Triki I, Auziol C, et al. 2008. Trio mediates netrin-1-induced Racl activation in axon outgrowth and guidance. Mol Cell Biol 28: 2314-2323.

Castellani V, Chedotal A, Schachner M, Faivre-Sarrailh C, Rougon G. 2000. Analysis of the L1-deficient mouse phenotype reveals cross-talk between Sema3A and L1 signaling pathways in axonal guidance. Neuron 27: 237-249.

Chalasani SH, Sabelko KA, Sunshine MJ, Littman DR, Raper JA. 2003. A chemokine, SDF-1, reduces the effectiveness of multiple axonal repellents and is required for normal axon pathfinding. J Neurosci 23: 1360-1371.

Chalasani SH, Sabol A, Xu H, Gyda MA, Rasband K, et al. 2007. Stromal cell-derived factor-1 antagonizes slit/ robo signaling in vivo. J Neurosci 27: 973-980.

Coate TM, Swanson TL, Copenhaver PF. 2009. Reverse signaling by glycosylphosphatidylinositol-linked Manduca ephrin requires a SRC family kinase to restrict neuronal migration in vivo. J Neurosci 29: 3404-3418.

Corset V, Nguyen-Ba-Charvet KT, Forcet C, Moyse E, Chedotal A, Mehlen P. 2000. Netrin-1-mediated axon outgrowth and cAMP production requires interaction with adenosine A2b receptor. Nature 407: 747-750.

Cowan CA, Henkemeyer M. 2001. The SH2/SH3 adaptor Grb4 transduces B-ephrin reverse signals. Nature 413: 174- 179 .

Cowan CW, Shao YR, Sahin M, Shamah SM, Lin MZ, et al. 2005. Vav family GEFs link activated Ephs to endocytosis and axon guidance. Neuron 46: 205-217. 
G.J. Bashaw and R. Klein

Davy A, Gale NW, Murray EW, Klinghoffer RA, Soriano P, et al. 1999. Compartmentalized signaling by GPIanchored ephrin-A5 requires the Fyn tyrosine kinase to regulate cellular adhesion. Genes Dev 13: 3125-3135.

Dontchev VD, Letourneau PC. 2002. Nerve growth factor and semaphorin $3 \mathrm{~A}$ signaling pathways interact in regulating sensory neuronal growth cone motility. J Neurosci 22: 6659-6669.

Egea J, Nissen UV, Dufour A, Sahin M, Greer P, et al. 2005. Regulation of EphA 4 kinase activity is required for a subset of axon guidance decisions suggesting a key role for receptor clustering in Eph function. Neuron 47: 515-528.

Fan X, Labrador JP, Hing H, Bashaw GJ. 2003. Slit stimulation recruits Dock and Pak to the roundabout receptor and increases Rac activity to regulate axon repulsion at the CNS midline. Neuron 40: 113-127.

Fawcett JP, Georgiou J, Ruston J, Bladt F, Sherman A, et al. 2007. Nck adaptor proteins control the organization of neuronal circuits important for walking. Proc Natl Acad Sci 104: 20973-20978.

Forsthoefel DJ, Liebl EC, Kolodziej PA, Seeger MA. 2005. The Abelson tyrosine kinase, the Trio GEF and Enabled interact with the Netrin receptor Frazzled in Drosophila. Development 132: 1983-1994.

Frank CA, Pielage J, Davis GW. 2009. A presynaptic homeostatic signaling system composed of the Eph receptor, ephexin, Cdc42, and CaV2.1 calcium channels. Neuron 61: 556-569.

Fritz JL, VanBerkum MF. 2000. Calmodulin and son of sevenless dependent signaling pathways regulate midline crossing of axons in the Drosophila CNS. Development 127: 1991-2000.

Galko MJ, Tessier-Lavigne M. 2000. Function of an axonal chemoattractant modulated by metalloprotease activity. Science 289: 1365-1367.

Georgakopoulos A, Litterst C, Ghersi E, Baki L, Xu C, et al. 2006. Metalloproteinase/Presenilin1 processing of ephrinB regulates EphB-induced Src phosphorylation and signaling. EMBO J 25: 1242-1252.

Gitai Z, Yu TW, Lundquist EA, Tessier-Lavigne M, Bargmann CI. 2003. The netrin receptor UNC-40/DCC stimulates axon attraction and outgrowth through enabled and, in parallel, Rac and UNC-115/AbLIM. Neuron 37: 53-65.

Gomez TM, Zheng JQ. 2006. The molecular basis for calcium-dependent axon pathfinding. Nat Rev Neurosci 7: $115-125$.

Hakeda-Suzuki S, Ng J, Tzu J, Dietzl G, Sun Y, et al. 2002. Rac function and regulation during Drosophila development. Nature 416: 438-442.

Hall A, Lalli G. 2010. Rho and Ras GTPases in axon growth, guidance, and branching. Cold Spring Harb Perspect Biol 2: a001818.

Hattori M, Osterfield M, Flanagan JG. 2000. Regulated cleavage of a contact-mediated axon repellent. Science 289: $1360-1365$.

Henkemeyer M, Orioli D, Henderson JT, Saxton TM, Roder J, et al. 1996. Nuk controls pathfinding of commissural axons in the mammalian central nervous system. Cell 86: $35-46$
Henley J, Poo MM. 2004. Guiding neuronal growth cones using Ca2+ signals. Trends Cell Biol 14: 320-330.

Henley JR, Huang KH, Wang D, Poo MM. 2004. Calcium mediates bidirectional growth cone turning induced by myelin-associated glycoprotein. Neuron 44: 909-916.

Hong K, Nishiyama M, Henley J, Tessier-Lavigne M, Poo M. 2000. Calcium signalling in the guidance of nerve growth by netrin-1. Nature 403: 93-98.

Hopker VH, Shewan D, Tessier-Lavigne M, Poo M, Holt C. 1999. Growth-cone attraction to netrin-1 is converted to repulsion by laminin-1. Nature 401: 69-73.

Hu H, Marton TF, Goodman CS. 2001. Plexin b mediates axon guidance in Drosophila by simultaneously inhibiting active rac and enhancing rhoa signaling. Neuron 32: $39-51$.

Hu H, Li M, Labrador JP, McEwen J, Lai EC, et al. 2005. Cross GTPase-activating protein (CrossGAP)/Vilse links the Roundabout receptor to Rac to regulate midline repulsion. Proc Natl Acad Sci 102: 4613-4618.

Itoh B, Hirose T, Takata N, Nishiwaki K, Koga M, et al. 2005. SRC-1, a non-receptor type of protein tyrosine kinase controls the direction of cell and growth cone migration in C. elegans. Development 132: 5161-5172.

Iwasato $\mathrm{T}$, Katoh $\mathrm{H}$, Nishimaru $\mathrm{H}$, Ishikawa $\mathrm{Y}$, Inoue $\mathrm{H}$, Saito YM, Ando R, Iwama M, Takahashi R, Negishi M, et al. 2007. Rac-GAP alpha-Chimerin regulates motorcircuit formation as a key mediator of EphrinB3/ EphA4 forward signaling. Cell 130: 742-753.

Janes PW, Saha N, Barton WA, Kolev MV, WimmerKleikamp SH, et al. 2005. Adam meets Eph: an ADAM substrate recognition module acts as a molecular switch for ephrin cleavage in trans. Cell 123: 291-304.

Jin Z, Strittmatter SM. 1997. Rac1 mediates collapsin-1induced growth cone collapse. J Neurosci 17: 6256-6263.

Jurney WM, Gallo G, Letourneau PC, McLoon SC. 2002. Rac1-mediated endocytosis during ephrin-A2- and semaphorin 3A-induced growth cone collapse. J Neurosci 22: 6019-6028.

Kao TJ, Palmesino E, Kania A. 2009. SRC family kinases are required for limb trajectory selection by spinal motor axons. J Neurosci 29: 5690-5700.

Knöll B, Drescher U. 2004. Src family kinases are involved in EphA receptor-mediated retinal axon guidance. J Neurosci 24: 6248-6257.

Law CO, Kirby RJ, Aghamohammadzadeh S, Furley AJ. 2008. The neural adhesion molecule TAG-1 modulates responses of sensory axons to diffusible guidance signals. Development 135: 2361-2371.

Levy-Strumpf N, Culotti JG. 2007. VAB-8, UNC-73 and MIG-2 regulate axon polarity and cell migration functions of UNC-40 in C. elegans. Nat Neurosci 10: 161-168.

Li X, Gao X, Liu G, Xiong W, Wu J, Rao Y. 2008. Netrin signal transduction and the guanine nucleotide exchange factor DOCK180 in attractive signaling. Nat Neurosci 11: $28-35$.

Li Y, Jia YC, Cui K, Li N, Zheng ZY, et al. 2005. Essential role of TRPC channels in the guidance of nerve growth cones by brain-derived neurotrophic factor. Nature 434: 894-898. 
Li W, Lee J, Vikis HG, Lee SH, Liu G, et al. 2004. Activation of FAK and Src are receptor-proximal events required for netrin signaling. Nat Neurosci 7: 1213-1221.

Li X, Saint-Cyr-Proulx E, Aktories K, Lamarche-Vane N. 2002. Rac1 and Cdc42 but not RhoA or Rho kinase activities are required for neurite outgrowth induced by the Netrin-1 receptor DCC (deleted in colorectal cancer) in N1E-115 neuroblastoma cells. J Biol Chem 277: 15207-15214.

Liebl EC, Forsthoefel DJ, Franco LS, Sample SH, Hess JE, et al. 2000. Dosage-sensitive, reciprocal genetic interactions between the Abl tyrosine kinase and the putative GEF trio reveal trio's role in axon pathfinding. Neuron 26: $107-118$.

Lim YS, McLaughlin T, Sung TC, Santiago A, Lee KF, O'Leary DD. 2008. p75(NTR) mediates ephrin-A reverse signaling required for axon repulsion and mapping. Neuron 59: 746-758.

Lin KT, Sloniowski S, Ethell DW, Ethell IM. 2008. Ephrin-B2 induced cleavage of EphB2 receptor is mediated by matrix metalloproteinases to trigger cell repulsion. J Biol Chem 283: 28969-28979.

Litterst C, Georgakopoulos A, Shioi J, Ghersi E, Wisniewski T, et al. 2007. Ligand binding and calcium influx induce distinct ectodomain $/ \gamma$-secretase-processing pathways of EphB2 receptor. J Biol Chem 282: 16155-16163.

Liu G, Beggs H, Jurgensen C, Park HT, Tang H, et al. 2004. Netrin requires focal adhesion kinase and Src family kinases for axon outgrowth and attraction. Nat Neurosci 7: $1222-1232$.

Liu G, Li W, Gao X, Li X, Jürgensen C, et al. 2007. p130CAS is required for netrin signaling and commissural axon guidance. J Neurosci 27: 957-968.

Lundstrom A, Gallio M, Englund C, Steneberg P, Hemphala J, et al. 2004. Vilse, a conserved Rac/Cdc42 GAP mediating Robo repulsion in tracheal cells and axons. Genes Dev 18: $2161-2171$.

Marler KJ, Becker-Barroso E, Martinez A, Llovera M, Wentzel C, et al. 2008. A TrkB/EphrinA interaction controls retinal axon branching and synaptogenesis. $J$ Neurosci 28: $12700-12712$.

McKenna WL, Wong-Staal C, Kim GC, Macias H, Hinck L, Bartoe JL. 2008. Netrin-1-independent adenosine A2b receptor activation regulates the response of axons to netrin- 1 by controlling cell surface levels of UNC5A receptors. J Neurochem 104: 1081-1090.

Meriane M, Tcherkezian J, Webber CA, Danek EI, Triki I, et al. 2004. Phosphorylation of DCC by Fyn mediates Netrin-1 signaling in growth cone guidance. J Cell Biol 167: 687-698.

Moore SW, Kennedy TE. 2006. Protein kinase A regulates the sensitivity of spinal commissural axon turning to netrin-1 but does not switch between chemoattraction and chemorepulsion. J Neurosci 26: 2419-2423.

Moore SW, Correia JP, Lai Wing Sun K, Pool M, Fournier AE, Kennedy TE. 2008a. Rho inhibition recruits DCC to the neuronal plasma membrane and enhances axon chemoattraction to netrin 1. Development 135: 2855-2864.

Moore SW, Sun KL, Xie F, Barker PA, Conti M, Kennedy TE. 2008b. Soluble adenylyl cyclase is not required for axon guidance to netrin-1. J Neurosci 28: 3920-3924.
Mumm JS, Kopan R. 2000. Notch signaling: from the outside in. Dev Biol 228: 151-165.

Newsome TP, Schmidt S, Dietzl G, Keleman K, Asling B, et al. 2000. Trio combines with dock to regulate Pak activity during photoreceptor axon pathfinding in Drosophila. Cell 101: 283-294.

Nishiyama M, Hoshino A, Tsai L, Henley JR, Goshima Y, et al. 2003. Cyclic AMP/GMP-dependent modulation of $\mathrm{Ca} 2+$ channels sets the polarity of nerve growth-cone turning. Nature 423: 990-995.

Nishiyama M, Von Schimmelmann M, Togashi K, Findley W, Hong K. 2008. Membrane potential shifts caused by diffusible guidance signals direct growth-cone turning. Nat Neurosci 11: 762-771.

Palmer A, Zimmer M, Erdmann KS, Eulenburg V, Porthin A, et al. 2002. EphrinB phosphorylation and reverse signaling: Regulation by Src kinases and PTP-BL phosphatase. Mol Cell 9: 725-37.

Pan D, Rubin GM. 1997. Kuzbanian controls proteolytic processing of Notch and mediates lateral inhibition during Drosophila and vertebrate neurogenesis. Cell 90: 271-280.

Parent AT, Barnes NY, Taniguchi Y, Thinakaran G, Sisodia SS. 2005. Presenilin attenuates receptor-mediated signaling and synaptic function. J Neurosci 25: 1540-1549.

Piper M, Salih S, Weinl C, Holt CE, Harris WA. 2005. Endocytosis-dependent desensitization and protein synthesis-dependent resensitization in retinal growth cone adaptation. Nat Neurosci 8: 179-186.

Ren XR, Ming GL, Xie Y, Hong Y, Sun DM, et al. 2004. Focal adhesion kinase in netrin-1 signaling. Nat Neurosci 7: 1204-1212.

Rooke J, Pan D, Xu T, Rubin GM. 1996. KUZ, a conserved metalloprotease-disintegrin protein with two roles in Drosophila neurogenesis. Science 273: 1227-1231.

Sahin M, Greer PL, Lin MZ, Poucher H, Eberhart J, et al. 2005. Eph-dependent tyrosine phosphorylation of ephexin1 modulates growth cone collapse. Neuron 46: 191-204.

Sasaki Y, Cheng C, Uchida Y, Nakajima O, Ohshima T, et al. 2002. Fyn and Cdk5 mediate semaphorin-3A signaling, which is involved in regulation of dendrite orientation in cerebral cortex. Neuron 35: 907-920.

Schimmelpfeng K, Gogel S, Klambt C. 2001. The function of leak and kuzbanian during growth cone and cell migration. Mech Dev 106: 25-36.

Segura I, Essmann CL, Weinges S, Acker-Palmer A. 2007. Grb4 and GIT1 transduce ephrinB reverse signals modulating spine morphogenesis and synapse formation. Nat Neurosci 10: 301-310.

Shekarabi M, Kennedy TE. 2002. The netrin-1 receptor DCC promotes filopodia formation and cell spreading by activating Cdc42 and Rac1. Mol Cell Neurosci 19: $1-17$.

Shekarabi M, Moore SW, Tritsch NX, Morris SJ, Bouchard JF, Kennedy TE. 2005. Deleted in colorectal cancer binding netrin-1 mediates cell substrate adhesion and recruits Cdc42, Racl, Pak1, and N-WASP into an intracellular signaling complex that promotes growth cone expansion. J Neurosci 25: 3132-3141. 
G.J. Bashaw and R. Klein

Shewan D, Dwivedy A, Anderson R, Holt CE. 2002. Age-related changes underlie switch in netrin-1 responsiveness as growth cones advance along visual pathway. Nat Neurosci 5: 955-962.

Shi L, Fu WY, Hung KW, Porchetta C, Hall C, et al. 2007. $\alpha 2$ chimaerin interacts with EphA4 and regulates EphA4dependent growth cone collapse. Proc Natl Acad Sci 104: 16347-16352.

Shim S, Goh EL, Ge S, Sailor K, Yuan JP, et al. 2005 XTRPC1-dependent chemotropic guidance of neuronal growth cones. Nat Neurosci 8: 730-735.

Song HJ, Ming GL, Poo MM. 1997. cAMP-induced switching in turning direction of nerve growth cones. Nature 388: $275-279$.

Song H, Ming G, He Z, Lehmann M, McKerracher L, et al. 1998. Conversion of neuronal growth cone responses from repulsion to attraction by cyclic nucleotides. Science 281: 1515-1518.

Stein E, Zou Y, Poo M, Tessier-Lavigne M. 2001. Binding of DCC by netrin-1 to mediate axon guidance independent of adenosine A2B receptor activation. Science 291: 1976-1982.

Swiercz JM, Kuner R, Behrens J, Offermanns S. 2002. Plexin-B1 directly interacts with PDZ-RhoGEF/LARG to regulate RhoA and growth cone morphology. Neuron 35: $51-63$.

Taniguchi Y, Kim SH, Sisodia SS. 2003. Presenilindependent " $\gamma$-secretase" processing of deleted in colorectal cancer (DCC). J Biol Chem 278: 30425-30428.

Terman JR, Kolodkin AL. 2004. Nervy links protein kinase a to plexin-mediated semaphorin repulsion. Science 303: 1204-1207.

Togashi K, von Schimmelmann MJ, Nishiyama M, Lim CS, Yoshida N, et al. 2008. Cyclic GMP-gated CNG channels function in Sema3A-induced growth cone repulsion. Neuron 58: 694-707.

Tomita T, Tanaka S, Morohashi Y, Iwatsubo T. 2006. Presenilin-dependent intramembrane cleavage of ephrin-B1. Mol Neurodegener 1: 2.

Toyofuku T, Yoshida J, Sugimoto T, Zhang H, Kumanogoh A, et al. 2005. FARP2 triggers signals for Sema3Amediated axonal repulsion. Nat Neurosci 8: 1712-1719.

Turner LJ, Nicholls S, Hall A. 2004. The activity of the plexin-A1 receptor is regulated by Rac. J Biol Chem 279: 33199-33205.

Vikis HG, Li W, Guan KL. 2002. The plexin-B1/Rac interaction inhibits PAK activation and enhances Sema4D ligand binding. Genes Dev 16: 836-845.

Wahl S, Barth H, Ciossek T, Aktories K, Mueller BK. 2000 Ephrin-A5 induces collapse of growth cones by activating Rho and Rho kinase. J Cell Biol 149: 263-270.
Wang GX, Poo MM. 2005. Requirement of TRPC channels in netrin-1-induced chemotropic turning of nerve growth cones. Nature 434: 898-904.

Watari-Goshima N, Ogura K, Wolf FW, Goshima Y, Garriga G. 2007. C. elegans VAB-8 and UNC-73 regulate the SAX-3 receptor to direct cell and growth-cone migrations. Nat Neurosci 10: 169-176.

Wegmeyer H, Egea J, Rabe N, Gezelius H, Filosa A, et al. 2007. EphA4-dependent axon guidance is mediated by the RacGAP $\alpha 2$-chimaerin. Neuron 55: 756-767.

Wong K, Ren XR, Huang YZ, Xie Y, Liu G, et al. 2001. Signal transduction in neuronal migration: roles of GTPase activating proteins and the small GTPase Cdc42 in the Slit-Robo pathway. Cell 107: 209-221.

Wouda R, Bansraj M, De Jong A, Noordermeer J, Fradkin L. 2008. Src family kinases are required for WNT5 signaling through the Derailed/RYK receptor in the Drosophila embryonic central nervous system. Development 135: 2277-2287.

Wu KY, Zippin JH, Huron DR, Kamenetsky M, Hengst U, et al. 2006. Soluble adenylyl cyclase is required for netrin-1 signaling in nerve growth cones. Nat Neurosci 9: $1257-1264$.

Xu NJ, Henkemeyer M. 2009. Ephrin-B3 reverse signaling through Grb4 and cytoskeletal regulators mediates axon pruning. Nat Neurosci 12: 268-276.

Yam PT, Langlois SD, Morin S, Charron F. 2009. Sonic hedgehog guides axons through a noncanonical, Srcfamily-kinase-dependent signaling pathway. Neuron 62: 349-362.

Yang L, Bashaw GJ. 2006. Son of sevenless directly links the robo receptor to rac activation to control axon repulsion at the midline. Neuron 52: 595-607.

Zheng JQ. 2000. Turning of nerve growth cones induced by localized increases in intracellular calcium ions. Nature 403: 89-93.

Zheng JQ, Poo MM. 2007. Calcium signaling in neuronal motility. Annu Rev Cell Dev Biol 23: 375-404.

Zhuang B, Su YS, Sockanathan S. 2009. FARP1 promotes the dendritic growth of spinal motor neuron subtypes through transmembrane Semaphorin6A and PlexinA4 signaling. Neuron 61: 359-372.

Zimmer G, Kastner B, Weth F, Bolz J. 2007. Multiple effects of ephrin-A5 on cortical neurons are mediated by SRC family kinases. J Neurosci 27: 5643-5653.

Zimmer M, Palmer A, Kohler J, Klein R. 2003. EphBephrinB bi-directional endocytosis terminates adhesion allowing contact mediated repulsion. Nat Cell Biol 5: 869-878. 


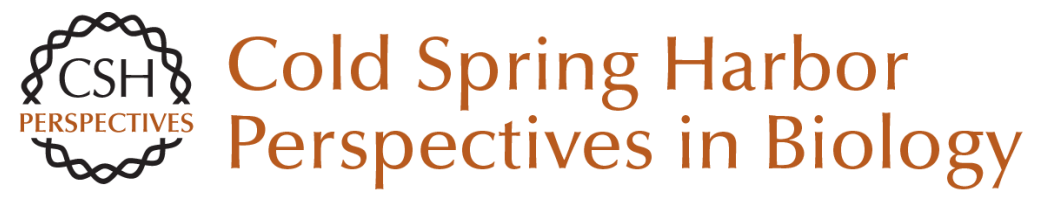

\title{
Signaling from Axon Guidance Receptors
}

\author{
Greg J. Bashaw and Rüdiger Klein
}

Cold Spring Harb Perspect Biol 2010; doi: 10.1101/cshperspect.a001941 originally published online March 24, 2010

\section{Subject Collection Neuronal Guidance}

\section{Mechanisms and Molecules of Neuronal Wiring: A Primer Alex L. Kolodkin and Marc Tessier-Lavigne \\ Guidance Molecules in Axon Pruning and Cell Death \\ Pierre Vanderhaeghen and Hwai-Jong Cheng \\ Initiating and Growing an Axon \\ F. Polleux and William Snider}

Navigating Intermediate Targets: The Nervous System Midline

Barry J. Dickson and Yimin Zou

Cellular Strategies of Axonal Pathfinding Jonathan Raper and Carol Mason

Guidance Molecules in Axon Regeneration Roman J. Giger, Edmund R. Hollis II and Mark H. Tuszynski

Signaling from Axon Guidance Receptors Greg J. Bashaw and Rüdiger Klein

Visual Map Development: Bidirectional Signaling, Bifunctional Guidance Molecules, and Competition

David A. Feldheim and Dennis D. M. O'Leary
Wiring the Brain: The Biology of Neuronal Guidance Alain Chédotal and Linda J. Richards

Guidance Molecules in Synapse Formation and

Plasticity Kang Shen and Christopher W. Cowan

The Growth Cone Cytoskeleton in Axon Outgrowth and Guidance Erik W. Dent, Stephanie L. Gupton and Frank B. Gertler

Topographic Mapping--The Olfactory System Takeshi Imai, Hitoshi Sakano and Leslie B. Vosshall

Self-avoidance and Tiling: Mechanisms of

Dendrite and Axon Spacing Wesley B. Grueber and Alvaro Sagasti

Trafficking Guidance Receptors Bettina Winckler and Ira Mellman

Axon Guidance Molecules in Vascular Patterning Ralf H. Adams and Anne Eichmann

Human Genetic Disorders of Axon Guidance Elizabeth C. Engle

For additional articles in this collection, see http://cshperspectives.cshlp.org/cgi/collection/

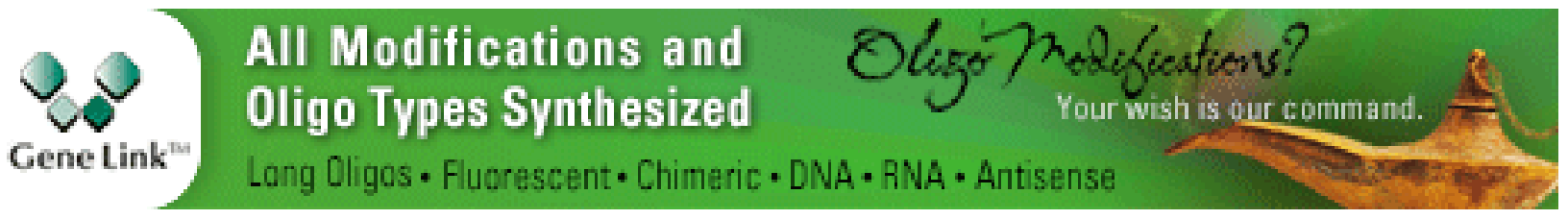

